\title{
Notas preliminares sobre o potencial de uso da experimentação no ensino de Geociências na educação básica
}

\author{
Renata Correia Costa \\ Mestranda no Programa de Pós-graduação \\ em Ensino e História de Ciências da Terra, \\ Instituto de Geociências, Unicamp. \\ recorreiacosta@gmail.com \\ Alfredo Borges De-Campos \\ Instituto de Geociências, Unicamp. \\ acampos@ige.unicamp.br \\ Cleonice Rocha \\ Departamento de Matemática e Física - \\ PUC, Goiânia, GO e professora visitante no \\ Instituto de Geociências - Unicamp \\ rcleonice@gmail.com
}

\begin{abstract}
PRELIMINARY Notes On The Potential Use Of Experiments IN TeACHING Of EARTH SCIENCES IN BASIC EDUCATION. This study reports a survey on the theoretical foundations that allowed experimentation to be considered as scientific and pedagogic methods and not just an empirical tool. Emphasis is placed on the contribution of the positivist and rationalist sciences along with inductive and deductive methods to the experimentation evolution process. The article focuses on the application of experimentation for Geosciences teaching, providing a brief history and a nowadays contextualization of experimentation and thus discussing the possibility of applying it on the theme environment (Tema Transversal Meio Ambiente) as proposed by National Curriculum Standards (PCNs). In closing, the article intends to show that experimentation can contribute to the construction of Geosciences knowledge in a contextualized, interdisciplinary, participatory and critical way. Citation: Costa R.C., De-Campos A.B., Rocha C. 2014. Notas sobre experimentação no ensino de Geociências na educação básica brasileira. Terræ Didatica, 10(3):383-393. http://www.ige.unicamp.br/terraedidatica/.
\end{abstract}

KEYWORDS: Experimentation, teaching, Geosciences.

RESUMO O presente estudo faz um levantamento de bases teóricas que permitiram à experimentação ser considerada um método científico e pedagógico e não somente uma prática empírica. Destacam-se as vertentes positivista e racionalista da Ciência juntamente com os pensamentos indutivo e dedutivo no processo de evolução da experimentação. O artigo tem como foco a análise da experimentação voltada para o ensino de Geociências; apresenta-se uma breve revisão bibliográfica, histórico e contextualização da experimentação na atualidade e sua possível aplicação no ensino de Geociências no Brasil com o Tema Transversal "Meio Ambiente", previsto nos Parâmetros Curriculares Nacionais - PCNs. Embora seja parte de uma pesquisa em andamento, o artigo propõe que a experimentação no âmbito do ensino das Geociências pode contribuir na busca pela construção do conhecimento de forma contextualizada, interdisciplinar, participativa e crítica.

PALAVRAS-CHAVE: Experimentação, ensino, Geociências. 


\section{Introdução}

Muitas de nossas ações cotidianas utilizam a experimentação como forma de comprovação ou refutação de ideias que nem sempre estão ligadas às investigações científicas, mas que empregam uma metodologia desenvolvida há séculos por cientistas que buscavam compreender melhor o fenômeno investigado.

Algumas definições da palavra experimentação encontradas nos dicionários trazem uma abordagem relacionada ao método científico, como o significado trazido pelo dicionário Priberam da Língua Portuguesa (2009) que diz: "experimentação é o ato de experimentar ou experenciar; um método científico que preconiza o conhecimento adquirido por prática, estudos, observação". Já para o Dicionário Aulete (2008),

“experimentação é a ação ou resultado de experimentar; é a investigação que, a partir de uma hipótese, busca observar e classificar determinado fenômeno em condições controladas".

Entretanto, quando a experimentação tornou-se um método científico? Quando ela passou a ser inserida nas investigações científicas? De acordo com Carpi e Egger (2008) o físico e matemático Abu Ali al-Hasan Ibn Al-Haitham, conhecido também por Alhazen [965-1040], dedicado ao estudo da luz e dos fenômenos ópticos, foi um dos primeiros cientistas a utilizar a evidência experimental para basear suas conclusões investigativas. Por meio de um experimento simples, que consistia na observação de um quarto escuro com um furo na parede e duas lanternas acesas em posições diferentes do lado de fora, Alhazen descobriu provas experimentais de que a luz não procedia do olho humano, mas que era emitida em linha reta por alguns objetos, nesse caso as lanternas. Embora partindo de um experimento simples, a metodologia científica utilizada foi bastante inovadora: desenvolver uma hipótese fundamentada em observações e utilizar um experimento para comprová-la.

Anterior à Alhazen, embora não apoiado em uma metodologia científica, o filósofo grego Aristóteles já reconhecia que era preciso possuir a noção juntamente com as experiências, e conhecer o universal e também o particular, caso contrário surgiriam muitos enganos. (Giordan 1999). Aristóteles afirmava também que o princípio da experiência era direcionador da pesquisa. (Rampazzo 2005). Muito tempo depois, em meados do século XVII, a experimentação recebeu contribuições da ciência positivista e passou a contribuir com a formulação de uma metodologia científica pautada na racionalização de procedimentos e formas de pensamento indutivas e dedutivas. (Giordan 1999)

Dentre as diversas possibilidades da experimentação como metodologia científica, podemos destacar os experimentos exploratórios; experimentos para quantificar a dimensão das relações entre as variáveis; e experimentos que fornecem evidências adicionais para complementar outros métodos de investigação (Carpi e Egger 2008).

No universo da experimentação aplicada ao ensino de Geociências nos ciclos básicos da educação formal esta traz a possibilidade de entender os processos envolvidos nos fenômenos investigados, não somente com a finalidade de confirmação das hipóteses teóricas, mas também abordando a questão do erro e das particularidades dos processos. Em especial no Brasil, com o respaldo do Tema Transversal "Meio Ambiente" sugerido pelos Parâmetros Curriculares Nacionais (PCNs), as Geociências podem por intermédio da experimentação cumprir seu papel interdisciplinar de forma abrangente e ao mesmo tempo contextualizada. Entende-se interdisciplinaridade como uma troca e cooperação entre diversos conceitos sobre um mesmo objeto, conforme Morin (2003).

O presente estudo objetivou fazer um levantamento de apoios teóricos sobre a metodologia da experimentação aplicada ao conhecimento científico moderno e realizar uma breve reflexão sobre a inserção de tal prática científica no ensino de Geociências na educação básica brasileira. Para conduzir o estudo, algumas obras chaves relativas ao tema experimentação foram consultadas e são analisadas ao longo do artigo.

\section{Raízes da experimentação moderna: as contribuições positivistas e racionalistas}

Em meados do século XVII as Ciências Naturais começaram a se consolidar e a experimentação ganhou espaço à medida que as leis formuladas deveriam passar pelo empirismo, formulação de hipóteses e verificação de coerência. Dessa forma, após reconhecer o problema a ser estudado o cientista deveria efetuar experimentos a fim de realizar observações cautelosas e coletar dados para registrá-los e divulgá-los na comunidade científica. Pondera-se que a busca por dados e observações 
originadas da etapa da experimentação permitiram a formulação de enunciados gerais a partir da análise de casos particulares contextualizados no experimento. Assim, tem-se o surgimento do método indutivo de investigação descrito por Francis Bacon [1561-1626] (Giordan 1999).

No método indutivo a experimentação tem o papel de levantar dados particulares provenientes de evidências empíricas que devem concordar com o enunciado genérico. Nesse caso não está aberta a possibilidade da contradição.

Contemporâneo a Bacon, Galileu Galilei [1564-1642] levanta a necessidade de desprendimento do cientista da natureza do pensamento filosófico e religioso, e com isso traz à discussão a questão do método. Galilei atribuiu a interpretação quantitativa da natureza e sustentou que a pesquisa científica deveria passar pelo momento analítico e sintético. O momento analítico está relacionado a observação complexa do fenômeno estudado, de seus elementos e suas partes. Durante esse momento o investigador propõem hipóteses para tentar explicar os elementos do fenômeno, e então adentra ao momento sintético que consiste em "repetir" o fenômeno através da experimentação. Nessa etapa, se a hipótese for confirmada, a mesma poderia se tornar lei. Galilei ressalta a importância da experimentação como exigência da ciência moderna (Rampazzo 2005).

Ainda no mesmo período histórico, René Descartes [1596-1650] se preocupou com a formulação de uma nova metodologia de investigação científica e atribuiu à experimentação um papel diferente daquele proposto por Bacon. O método dedutivo de investigação proposto por Descartes passa a reconhecer a influência do enunciado geral sobre eventos científicos particulares à medida que o caminho entre o enunciado genérico e o caso particular seja preenchido com experimentos (Giordan 1999).

Descartes (1996) em seu livro "Discurso do método" afirma que as experiências são cada vez mais necessárias à medida que se avança no conhecimento. E, nesse sentido, a princípio é necessário ater-se às experiências mais simples - perceptíveis aos sentidos e que não podem ser ignoradas, do que procurar experiências raras e complexas que levem ao engano, por ainda não serem conhecidas suas determinantes mais comuns.

Os três teóricos acima são considerados os fundadores da ciência moderna, pois realizaram suas pesquisas com a finalidade de desenvolver métodos científicos racionais que fizeram críticas ao pensamento aristotélico que se fundamentava na experimentação com base apenas na observação.

No contexto da ciência moderna, a experimentação ganha um caráter metodológico e não somente empirista. A experiência passa a ser parte fundamental da pesquisa científica, seja para confirmar ou refutar hipóteses (Barolli et al. 2010). Vale ressaltar que no método dedutivo proposto por Descartes há espaço para a refutação do enunciado geral, trazendo novamente a possibilidade de outros experimentos e também novos resultados.

No âmbito do ensino de Geociências na educação básica, são esses mesmos princípios que norteiam o uso da experimentação, contudo levando em consideração os propósitos e objetivos que se deseja cumprir e a maneira de organizá-los e construí-los.

\section{Contextualização e breve histórico da experimentação no ensino de Geociências no Brasil}

Galliazi et al. (2001) aponta que em tempos recentes as atividades experimentais adentraram as escolas a partir do trabalho desenvolvido nas universidades, com o objetivo de melhorar a aprendizagem dos alunos sobre os conteúdos científicos. Percebeu-se nesse momento que era necessário difundir os estudos científicos também nas escolas básicas, além de investir na formação dos professores.

Como marco referencial dessa tendência, a partir da década de 60 do século XX alguns projetos relacionados à experimentação e ensino de Ciências foram desenvolvidos nos Estados Unidos e, posteriormente, traduzidos e divulgados para outros países. De acordo com Lorenz (2008),

“(...) as críticas ao ensino secundário, impulsionadas pelos acontecimentos internacionais, levaram o governo norte-americano a promover grandes projetos para a reformulação do currículo, especialmente com referência ao ensino de Ciências" (Lorenz 2008:10).

A cooperação entre governo americano, professores, educadores e cientistas resultou na elaboração de novos cursos ou projetos de Ciências, como: o PSSC (Physical Science Study Committee) e o IPS (Introductory Physical Science) voltados para o ensino de Física; o BSCS (Biological Science Curriculum Study) para a Biologia; o CBA (Chemical Bond 
Approach) e o CHEM Study (Chemical Educational Material Study) para a Química; e o ESCP (Earth Science Curriculum Project) para as Geociências. Esses projetos se diferenciaram por desenvolver materiais como livros didáticos, manuais de laboratório, guias para o professor, equipamentos de laboratório, filmes, estudos de caso, leituras suplementares, materiais para alunos com necessidades especiais, entre outros (Lorenz 2008).

Segundo Lorenz (2008), todos esses projetos curriculares foram baseados em novo paradigma que propunha uma conceituação inovadora quanto à natureza da Ciência, o processo científico e o ensino de Ciências. Entre os princípios que nortearam a elaboração do novo paradigma, dois se destacam. O primeiro deles foi baseado nos argumentos levantados por cientistas e professores na Conferência de Woods Hole, em 1959, publicados no livro "O Processo da Educação" (The Process of Education), escrito por Jerome Bruner, que exalta a importância da "estrutura" das disciplinas científicas no ensino. Os argumentos dos participantes da conferência concordavam que os conceitos das Ciências não poderiam ser estudados de forma isolada, mas era necessário unificar os temas para facilitar a compreensão dos conteúdos. O segundo princípio foi articulado em um discurso dado em 1961, pelo professor da Universidade de Chicago e membro da equipe do projeto BSCS (Biological Science Curriculum Study), Joseph Schwab. Em seu discurso, Schwab afirmou que os conteúdos das Ciências não deveriam ser ensinados como uma "retórica de conclusões", mas sim, como processos contínuos de investigação. Para ele, o aluno deveria participar do processo científico para poder experimentar a Ciência em sua forma mais correta. Para isso, o professor deveria empregar o "método da descoberta", ou seja, ensinar o aluno a elaborar perguntas, buscar evidências, e avaliar os resultados das investigações (Schwab 1962 apud Lorenz 2008).

Embora significativo avanço foi alcançado nesse período, Guimarães (2010) pondera que o foco da experimentação nesta época era formar "mini-cientistas" utilizando como metodologia de ensino a redescoberta, no entanto, de acordo com essas propostas o método científico se convertia em uma receita que resolveria qualquer problema. Nesse tipo de proposta quase sempre a experiência é utilizada apenas como ilustração da teoria, seguindo uma "receita de bolo" em que nada deve sair do controle ou chegar a um resultado inesperado.

De acordo com Galiazzi et al. (2001) a trajetória do ensino experimental nas escolas intentou ser uma inovação, mas algumas das propostas carregavam em si princípios empiristas que contribuíram para a manutenção de ideias irrefletidas sobre a importância da experimentação no ensino. Nesse sentido, Guimarães (2010) observa que a metodologia da experimentação não deve ser baseada em receitas e roteiros que os alunos devam seguir para apresentar resultados já esperados pelo professor e, muito menos, que a construção do conhecimento se dê a partir de meras observações. Para o autor, "fazer ciência, no campo científico, não é ateórico" (Guimarães 2010).

Para Giordan (1999) e Francisco Jr. et al. (2008) a experimentação pode ser trabalhada de duas formas: ilustrativa e investigativa. A experimentação ilustrativa geralmente é utilizada para demonstrar conceitos ou teorias trabalhadas anteriormente, sem muitas propostas problematizadoras ou discussão dos resultados. A experimentação investigativa, de outra forma, é empregada anteriormente à discussão sobre o tema em interesse, como forma de levantar hipóteses por intermédio da observação, problematização e discussão da experiência. Também a partir do ponto de vista da utilidade da experimentação no ensino, podemos agrupar as práticas experimentais em dois grandes grupos: demonstrações fechadas e demonstrações abertas. As demonstrações fechadas trabalham a experimentação como ilustração de fenômenos. Nessa prática, é o professor quem assume o controle sobre a execução do experimento e seus resultados. As atividades experimentais fechadas possuem a figura do professor como ponto central. Já nas demonstrações abertas, há flexibilidade para discussões, reflexões e participação de todos os indivíduos envolvidos na execução da atividade experimental, ou seja, alunos e professor.

Considerando o exposto acima, observa-se que ao longo do tempo os métodos e práticas de ensino que utilizam a experimentação são alterados de acordo com o momento histórico, político e econômico pelo qual a sociedade está passando. O quadro também não foi diferente com a experimentação aplicada ao ensino de Geociências na sala de aula, desde o nível básico até o ensino superior. No Brasil, foram desenvolvidos alguns trabalhos que contribuíram com discussões e propostas pertinentes sobre o ensino de Geociências por meio da experimentação, entre eles Paschoale e Carneiro (1976), Gonçalves et al. (1994), Carneiro e Negrão (1995) e Cunha e Carneiro (1996). 
Amaral (2014) faz um resgate histórico dos principais acontecimentos que contribuíram com a dispersão do ensino de conteúdos de Geociências no Brasil e faz importante menção a experimentação. Entre eles a criação da Fundação Brasileira para o Desenvolvido do Ensino de Ciências (FUNBEC) em 1967 no campus da USP - São Paulo que contribuiu na confecção e distribuição de recursos didáticos, muitos deles tendo como base a experimentação, além de sediar um Centro de Treinamento de Professores de Ciências do Estado de São Paulo (CECISP) para treinar e difundir entre os professores novos projetos e materiais didáticos voltados para o ensino de Ciências da Natureza e Matemática. Outro marco importante para as Geociências no Brasil foi a realização da tradução e adaptação do ESCP (Earth Science Curriculum Project) no ano de 1973, com a publicação do primeiro volume do livro intitulado "Investigando a Terra", onde a experimentação aparece com papel de destaque como metodologia de ensino. Amaral (2014) destaca também o desenvolvimento de ideias inovadoras no campo da Pedagogia em meados da década de 1970 que repercutiram nas discussões sobre o processo de ensino-aprendizagem em diferentes níveis de ensino.

De acordo com Imbernon et al. (1999), desde o fim da década de 1950 o conceito de alfabetização científica vem sendo divulgado. Entre as diversas publicações sobre o tema, uma delas propõe estágios da alfabetização científica, sendo eles: alfabetização nominal, funcional, conceitual, procedimental e multidimensional. O último estágio desse processo individual supera as noções procedimentais da ciência e avança para a compreensão da natureza da Ciência, da história das ideias científicas e de seus papeis na vida social e pessoal (Bybee 1997 apud Imbernon et al. 1999). Segundo o autor, o ensino de Geociências nas escolas deve assumir o papel de elevar nossos alunos ao estágio mais complexo dessa alfabetização científica, para promover além dos conhecimentos teóricos a reflexão acerca de sua aplicabilidade e função na realidade social.

Em relação ao ensino de Geociências nas escolas, Imbernon et al. (2009) ponderam que a falta de preparação específica dos professores para agregar por meio da prática educativa o conhecimento científico ao cotidiano dos alunos, promovendo desta forma o distanciamento entre o ensino de Ciências na escola e a apropriação do conhecimento científico, interfere na formação de cidadãos críticos e atuantes. Os autores afirmam que a falta de sentido com que os conteúdos científicos apresentam-se para os alunos, e a falta de conexão lógica entre os conteúdos teóricos e o mundo real, muitas vezes, é a causa de um dos maiores problemas no ensino de Ciências e consequentemente de Geociências. "A efetiva participação do aluno na obtenção do conhecimento é uma das chaves para que o aluno passe de seu comportamento de passividade à responsabilidade pelo seu próprio aprendizado" (Imbernon et al. 2009).

De acordo com Imbernon et al. (2009) e Ledley et al. (2012), atualmente vemos muitas pesquisas na área de experimentação ligada às Geociências que buscam de forma inovadora inserir a experimentação, não com um fim em si própria, mas como uma forma de estimular a curiosidade para responder os porquês, criar conexão ao invés de complementação entre teoria e prática e compreender os processos que atuam em um determinado fenômeno.

Nessa direção, autores como Guimarães (2010) e Imbernon et al. (2009) argumentam a favor da "aprendizagem significativa", definida por Ausubel (2003 apud Tavares 2004) como um conhecimento que promove autonomia e articulação entre o ser humano e o meio, capacitando-o a se apropriar da informação e transformá-la em conhecimento. Para tanto, todo processo da atividade experimental deve ser discutido e retomado ao longo do desenvolvimento da atividade para que a mesma não se torne apenas uma ilustração daquilo que já está pronto. Quando alguns erros ou resultados inesperados ocorrem durante essas atividades, surge a oportunidade para levantar questionamentos sobre o "fazer ciência”, que é construído passo-a-passo, à medida que novos entraves, aparentemente sem respostas, se apresentam aos pesquisadores. Assim, a aprendizagem significativa abre uma nova janela para o ensino de Geociências por meio da experimentação.

\section{Reflexões sobre 0 uso atual da experimentação didática em Ciências e Geociências: análise de alguns estudos de referência}

Para abordar esse tópico foram selecionados três, dentre inúmeros trabalhos, que servem como referência para o estudo da experimentação aplicada às atividades didáticas em Ciências e Geociências em ambiente escolar acadêmico. Tais trabalhos apontam não somente a importância da 
experimentação como metodologia, mas também trazem à discussão as vertentes de compreensão e aplicabilidade do método.

O primeiro artigo analisado é o Laboratorio didáctico de ciencias: caminos de Investigación (Barolli et al. 2010) no qual é feito um levantamento de bases teóricas sobre o laboratório didático de Ciências. A princípio os autores destacam que as investigações sobre o tema receberam maior destaque a partir dos anos 1980 com o empenho de pesquisadores e professores preocupados em desenvolver metodologias e estratégias para aulas práticas com ênfase em trabalhos práticos experimentais em laboratórios.

O artigo traz contribuições de diversos autores que pesquisam o uso da experimentação em aulas de laboratório didático no ensino de Ciências e discute as controvérsias funcionais do laboratório didático, trazendo diferentes visões sobre as funções atribuídas às aulas de laboratório e como as mesmas contribuem no processo de ensino aprendizagem. Os autores buscam uma reflexão a respeito das funcionalidades do laboratório didático a partir de diferentes concepções sobre ciência e educação e expõem uma investigação sobre os processos de coleta e interpretação de dados experimentais.

Como mensagem final, os autores questionam a falta de exploração e estudo do laboratório em seu caráter de ambiente cognitivo, das experiências de aprendizagem que ali acontecem e do tratamento da coleta e interpretação dos dados obtidos, em contraposição a maior atenção dada à organização e montagem dos experimentos e postulam que esse é o endereçamento que a experimentação deve seguir.

O segundo trabalho analisado intitula-se $\mathrm{La}$ construcción de problemas en el laboratorio durante la formación del profesorado: una experiencia didáctica (Cortés Gracia et al. 2006). Esse artigo traz os resultados de uma experiência didática construída com professores em formação em educação primária na área de didática das Ciências.

O trabalho discute a resolução de problemas como um modo de conceber as atividades educativas em sala de aula e, dentro desse contexto, encontram-se as práticas de laboratório como estratégia didática no planejamento e resolução de problemas. O texto utiliza como marco teórico de referência o desenvolvimento de habilidades cognitivas, por meio de uma ciência que ensine a pensar, fazer, regular a própria aprendizagem e trabalhar em interação; as práticas de laboratório como meio de manifestar sua própria epistemologia; e a organização de sua atuação e regulação da própria aprendizagem (Séré 2002, Sardá e Sanmartí 2000 apud Cortés Garcia et al. 2006).

O artigo apresenta o modelo de indagação dirigida pelo professor que pressupõe conexão com o conhecimento prévio; exploração de experiências manipulativas; análise e interpretação de dados; ampliação de conhecimentos e habilidades; revisão do que foi aprendido e como foi aprendido. Nesse ponto é levantada a questão da formação de um professor preparado para utilizar esse tipo de didática.

Assim, o artigo discute a formação inicial de professores atrelada ao ensino de Ciências como um processo de indagação dirigida, e as limitações na formação de profissionais ligados a didática das Ciências experimentais. É apontada a necessidade de integrar um currículo para a ciência na escola que inclua a participação ativa dos estudantes e proponha uma ciência que facilite a formação de cidadãos cientificamente cultos. (Jiménez Aleixandre 1998, 2003, Paixao y Cachapuz 1999, Cañal 2000 apud Cortés Garcia et al. 2006). Além disso, o artigo destaca a metodologia de $\mathrm{V}$ do Gowin como uma ferramenta interessante nos trabalhos em laboratório, já que preconiza a interação entre a prática e o saber, concedendo à atividade a tarefa de buscar respostas as perguntas centrais da pesquisa.

$\mathrm{O}$ artigo traz uma experiência desenvolvida com estudantes do curso de especialidade em Educação Primária, com um total de 600 estudantes, com duração de 40 horas teóricas e práticas. Uma parte dessas horas foi dedicada às práticas dirigidas pelo professor destinadas a conhecer e utilizar materiais e técnica usuais em laboratórios. O restante das horas foi focada em pequenas investigações propostas, onde os alunos deveriam encontrar respostas e ou soluções para problemas por meio de atividades experimentos em laboratório. Nessa etapa é relatada todas as fases da atividade prática desde as concepções iniciais sobre o problema até a análise dos resultados experimentais, bem como as atitudes dos alunos mediante o modelo didático proposto.

Os aspectos positivos da experiência didática listados pelos autores são a possibilidade de desenvolver espaços de reflexão durante o processo de ensino-aprendizagem das Ciências experimentais; e dentre os aspectos negativos é apontada a dificuldade em identificar problemas no mundo natural, e em expressar os saberes e as próprias ideias.

O terceiro artigo analisado, denominado $A$ 
two-week guided inquiry project for an undergraduate Geomorphology course (Field 2003), reporta as bases teórico-metodológicas de um projeto de indagação dirigida desenvolvido na disciplina Geomorfologia. Nesse projeto a experimentação utilizou cinco recursos bastante comuns nas pesquisas em Geomorfologia (trabalhos de campo, mapas topográficos, fotografias aéreas, literatura científica e montagem de experimentos em laboratório) como estrutura para a investigação da questão problema.

Como etapas da experimentação, o autor utiliza uma hierarquia de procedimentos que se inicia pela formulação da questão-problema onde por meio do uso de fotografias aéreas e identificação de problemáticas geomorfológicas, os estudantes listaram suas ideias, hipóteses e possíveis explicações sobre uma determinada questão-problema. $\mathrm{Na}$ geração de hipóteses, os alunos consideraram os possíveis recursos que poderiam ser utilizados para investigar a questão-problema e literaturas específicas sobre o tema sugeridas pelo professor. Trabalho de campo para reconhecimento da questão-problema e coleta de dados acompanhado de interpretação de mapas topográficos, séries históricas de fotografias aéreas, constituíram a parte inicial da experimentação posterior a definição da questão-problema e elaboração da hipótese a ser testada. Complementarmente, os autores construíram um experimento em laboratório para simular o problema que foi investigado em campo. O artigo ilustra bem o papel atual da experimentação para o ensino de Geociências, o qual é pautado na experimentação como meio para se compreender problemas e discutir conceitos nessa área do conhecimento.

Em síntese, os três estudos analisados apontam para 1) necessidade da experimentação se centrar mais no processo ensino-aprendizagem e 2) considerar a experimentação como ferramenta didático-pedagógica adequada para abordar, investigar, discutir e eventualmente solucionar problemas em Ciências e Geociências.

\section{0 meio ambiente como Tema Transversal para 0 ensino de Geociências no Brasil}

Segundo Carneiro et al. (2004), o ensino de Geociências na educação básica brasileira ainda se faz muitas vezes de modo fragmentado entre as disciplinas escolares de Ciências do ensino fundamental Geografia, Física, Química e Biologia. Isso talvez se deva ao fato de que cada disciplina é encarregada de estudar uma esfera específica do Sistema Terra. Corroborando essa argumentação, Batista et al. (2009) ponderam que a experiência e o pensamento crítico em Ciências tendem a ficar mais distantes da escola, pois está fragmentado em diversas disciplinas que oferecem um volume enorme de conteúdos propostos pelos currículos, visão que também é compartilhada por Toledo (2002).

Algumas dessas disciplinas, como Ciências no ensino fundamental e Química no ensino médio, contam com número considerável de pesquisas relacionadas ao uso de experimentação em suas práticas, isso possivelmente ocorre porque as disciplinas relacionadas às Ciências Naturais carregam em si uma natureza experimental, pois seu conhecimento científico evolui à medida que suas hipóteses ou teorias são apoiadas por meio das evidências experimentais (Moreira e Axt 1991 apud Rodrigues et al. 2012).

Dessa forma, torna-se mais coerente abordar os temas das Geociências a partir do uso da experimentação de forma interdisciplinar, como propõe Cuello Gijón (1988) em seu artigo La Geologia como área interdisciplinar, integrando os conhecimentos específicos de cada disciplina em busca de um ensino contextualizado e significativo. Partindo desse ponto de vista, os Parâmetros Curriculares Nacionais (PCNs) sugerem temas cabíveis a todas as disciplinas que devem ser trabalhados de forma interdisciplinar, os quais são denominados Temas Transversais. Segundo os PCNs (Brasil 1997) a transversalidade implica integração das áreas de conhecimento e um compromisso com as relações interpessoais na esfera escolar.

Um dos Temas Transversais propostos pelos PCN's é o Meio Ambiente, pois cumpre com os critérios adotados para a eleição dos temas, sendo eles: urgência social, abrangência nacional, possibilidade de ensino e aprendizagem no ensino fundamental, favorecer a compreensão da realidade e a participação social (Brasil 1997).

A principal função do trabalho com o Tema Transversal Meio Ambiente é contribuir para a formação de cidadãos conscientes, aptos a decidir e a atuar na realidade socioambiental de modo comprometido com a vida, com o bem-estar de cada um e da sociedade, local e global. Nesse sentido a atividade experimental deve estar fundamentada para além da observação, inserindo a teoria, reflexão do indivíduo, questões sociais e culturais, objetivando o desenvolvimento pessoal do aluno a partir da problematização das observações experimentais 
e o diálogo (Guimarães 2010).

Sob o ponto vista interdisciplinar ligado por uma temática em comum, no caso o meio ambiente, a experimentação pode ser utilizada para investigar processos naturais e interferências antrópicas que muitas vezes não são perceptíveis aos nossos olhos.

Nessa direção podemos destacar o artigo de Ribeiro et al. (2007) que trabalha sob uma perspectiva interdisciplinar a partir da concepção do ciclo da água. Os autores desenvolveram a pesquisa em uma escola municipal com a interação entre a pesquisadora, a professora de Ciências e a professora de Geografia. O objetivo era promover uma atividade educativa com caráter interdisciplinar sobre o ciclo da água. Durante o desenvolvimento da atividade, perceberam-se algumas dificuldades que precisavam ser superadas, como o ensino de modelos reduzidos do ciclo da água que não levam em conta todos os processos envolvidos e os restringem apenas ao subciclo atmosférico, e a ausência de percepção da relação entre relevo e circulação da água. Para tanto, foram desenvolvidas atividades e roteiros de campo, elaboração de modelos de argila de uma microbacia e representação por meio de desenhos do ciclo da água, este como forma de avaliação da atividade. Durante o processo de desenvolvimento, os autores destacam a importância do espaço de interação criado entre as duas disciplinas e como as experiências docentes foram determinantes na forma de trabalho e avaliação dos estudantes. Por fim, o trabalho expõe a resistência e permanência de modelos mentais simplificados sobre o ciclo da água que foram reproduzidos pelos alunos mesmo após todas as atividades desenvolvidas.

Outro artigo interessante sobre a interdisciplinaridade em Geociências, de autoria de Piranha e Carneiro (2006), destaca a importância da educação e do pensamento científico no contexto social, tecnológico e ambiental contemporâneo amparado por documentos oficiais para a educação brasileira como os PCNs (1997) e a Lei de Diretrizes e Bases da Educação nacional - LDB (1996). Neste artigo, os autores destacam o conceito de interdisciplinaridade e a necessidade de uma educação voltada para a formação de cidadãos. O artigo ampara-se em fundamentos teóricos calcados na concepção de Sistema Terra sob uma visão holística do planeta, bem como bases para uma educação em Ciências da Terra (Williams 2002, Anguita 1994, Orion 2001 apud Piranha e Carneiro 2006).

A pesquisa que norteou o artigo desenvolveu- -se no âmbito do Projeto Geo-Escola realizado no município de São José do Rio Preto - São Paulo, teve a participação de professores de Ciências e Geografia e objetivou avaliar possíveis contribuições das Geociências para a educação escolar. Por meio de cursos de capacitação, os professores puderam complementar sua formação básica e inserir suas novas práticas em atividades interdisciplinares que trouxeram resultados bastante positivos no processo de ensino-aprendizagem de Geociências, como a motivação para utilizar recursos didáticos diferenciados e promover integração de conteúdos de diversas disciplinas a partir de um tema central.

Também Gebara e Kulaif (2007) questionam as limitações dos modelos tradicionais de ensino-aprendizagem e propõe uma adequação na formação inicial de professores como meio para se alcançar um ensino de qualidade sob a perspectiva interdisciplinar. As autoras discutem alguns entraves calcados no ensino de Geociências e Geologia nas escolas brasileiras, como a inexistência das ciências geológicas no currículo comum, a ausência de materiais geológicos de qualidade para substanciar a prática educativa dos professores, e a não permissão para a atuação de geólogos no ensino básico. O trabalho foi desenvolvido junto a professores do ensino básico que participaram do Projeto Fapesp/Petrobrás Ambiental. O objetivo era trazer à discussão os significados do conceito de interdisciplinaridade. Para isso, as autoras realizaram um levantamento das concepções prévias sobre o tema durante uma oficina sobre interdisciplinaridade. Como resultado, as autoras destacaram que embora haja possibilidade de integração entre disciplinas escolares, isso não significa que a interdisciplinaridade esteja bem fundamentada e sistematizada nas práticas docentes, embora haja concordância com a necessidade de superar a visão fragmentada do conhecimento para uma efetiva melhoria na qualidade do ensino.

Quanto ao uso da experimentação, a partir de uma atividade experimental é possível aguçar o pensamento para além daquilo que é visível, levando à discussão os elementos que constituem o sistema em análise, a percepção das mudanças ocorridas, e as possíveis consequências que serão originadas por desequilíbrios no sistema.

Um exemplo de experimento que pode ser utilizado em sala de aula para abordar o Tema Transversal Meio Ambiente é um protótipo de reator anaeróbico para tratamento de esgoto doméstico desenvolvido por Kondo e Rosa (2007). Os autores 
fazem uma discussão prévia sobre a importância do tratamento de esgoto doméstico, e propõem a construção de um experimento que representa uma estação de tratamento de esgoto por processo anaeróbico na qual, sob perspectiva interdisciplinar, conceitos científicos e princípios de funcionamento da estação são abordados e discutidos.

Assim como esse experimento, muitos outros em Geociências podem ser elaborados de acordo com os objetivos pretendidos e dentro do escopo do Tema Transversal Meio Ambiente. O importante é que eles sejam bem planejados, desde sua confecção até as discussões e análise de resultados. Como exposto anteriormente é preciso que a atividade seja conduzida com a finalidade de construir conhecimento científico interdisciplinar, mostrando que teoria e prática não caminham isoladas, mas pelo contrário, dão suporte uma à outra.

\section{Considerações finais}

Os artigos analisados e utilizados como referencial a respeito do uso da experimentação no ensino de Geociências oferecem um leque de possibilidades e exemplos do uso dessa metodologia em sala de aula com alunos de diversos níveis de ensino. No entanto, não existe na estrutura disciplinar do ensino fundamental e médio brasileiro uma disciplina específica de Geociências. Dessa forma, o Tema Transversal Meio Ambiente, proposto pelos PCNs, abre um espaço muito interessante para o ensino de Geociências na educação básica, porque propõem que todas as disciplinas trabalhem de forma interdisciplinar. Nesse sentido, ao invés de se ensinar Geografia ou Ciências de forma separada, por exemplo, é possível unificá-las com um tema em comum: o meio ambiente. Tendo o propósito de investigar as complexas relações que permeiam o ambiente natural e o ambiente humano como pontos em comum, a experimentação traz possibilidades para o estudo detalhado, participativo e crítico do processo de investigação. Embora a pesquisa ainda esteja em andamento, os exemplos analisados indicam que, aplicando-se a experimentação no ensino das Geociências, é possível produzir conhecimento científico na escola com base na interação entre professores e alunos pesquisadores.

\section{Referências}

Amaral I.A.do. 2014. Raízes da mudança curricular ocorrida em 1973 na USP. Terre Didatica, 10(3):(esta edição). URL: http:// www.ige.unicamp.br/terraedidatica/.

Anguita F.V. 1994. Geología, ciencias de la Tierra, ciencias de la naturaleza: paisaje de un aprendizaje global. Enseñanza de las Ciencias, 12(1):15-21.

Ausubel D.P. 2003. Aquisição e retenção de conhecimentos: uma perspectiva cognitiva. Lisboa: Ed. Plátano.

Barolli E., Laburú C.E., Guridi V.M. 2010. Laboratorio didáctico de ciencias: caminos de investigación. Rev. Electr. Enseñanza de las Ciencias, 9(1):88-110.

Batista M.C., Fusinato P.A., Blini R.B. 2009. Reflexões sobre a importância da experimentação no ensino de física. Acta Scientiarum. Humanand Social Sciences, 31(1):43-49. Janeiro 2009. URL: http:// periodicos.uem.br/. Acesso: 15.07.2013.

Brasil. 1997. Parâmetros curriculares nacionais: apresentação dos temas transversais, ética. Brasília: MEC/ SEF. 146p.

Brasil. 1997. Parâmetros curriculares nacionais: introdução aos parâmetros curriculares nacionais. Brasília: MEC/SEF. 126p.

Brasil. 2010. LDB: Lei de Diretrizes e Bases da Educação Nacional: lei no 9.394, de 20 de dezembro de 1996. $5^{a}$ ed. Brasília: Câmara dos Deputados/Coordenação Edições Câmara. 60p.

Bybee, R. 1997. Towards an Understanding of Scientific Literacy. Graeber,W e Bolte, C. (Eds).

Cañal P. 2000. El conocimiento profesional sobre las ciencias y la alfabetización científi ca en Primaria. Alambique, 24: 46-56.

Carneiro C.D.R., Negrão O.B.M. 1995. Busqueda incessante. Rev. de la Enseñanza de las Ciencias de la Tierra, 3(1):61-62. URL: http://www.raco.cat/ index.php/ECT/article/view/89237/141665. Acesso 07.09 .2014 .

Carneiro C.D.R., Toledo M.C.M., Almeida F.F.M. 2004. Dez motivos para a inclusão de temas de Geologia na Educação Básica. Rev. Bras. Geoc. 34(4):553-560.

Carpi A., Egger A. 2008. Métodos de Investigación: experimentación. In: Visionlearning Vol. POS-1(7), 2008. Estados Unidos da América.

Cortés Gracia A.L., Gándara Gómez M. 2006. La construcción de problemas en el laboratorio durante la formación del profesorado: una experiencia didáctica. Enseñanza de Las Ciencias, 25(3):435-450.

Cuello Gijón A. 1988. La geología como area interdisciplinar. Henares, Rev. Geol., 2:367-387.

Cunha C.A.L.; Carneiro C.D.R. 1996. Estudo das transformações terrestres por meio das formas fixadas uma experiência de metodologia de ensino. In: Simp. de la Enseñanza de Geología.1996. Logroño: AEPECT. Rev. de la Enseñanza de las Ciencias de la Tierra, 4(n. extra):51-59. 
Descartes R. 1996. Discurso do método. São Paulo: Martins Fontes. 102p.

Dicionário Priberam da Língua Portuguesa 2010. URL: http://www.priberam.pt/dlpo/dlpo. aspx?pal = chave [consultado em 2009-04-07]. Acesso: 15.07.2013.

Field J. A two-week guided inquiry project for an under - graduate Geomorphology course. 2003. Journal of Geoscience Education, 51(2):255-261.

Francisco Jr W.E., Ferreira L.H., Hartwig D.R. Experimentação Problematizadora: Fundamentos Teóricos e Práticos para a Aplicação em Salas de Aula de Ciências. Química Nova na Escola, 30:34-41.

Galiazzi M.C. et al. 2001. Objetivos das atividades experimentais no ensino médio: a pesquisa coletiva como modo de formação de professores de ciências. Ciência e Educação, 7(2):249-263. Agosto 2001. URL: http://www.scielo.br/pdf/ciedu/ v7n2/08.pdf. Acesso: 15.07.2014.

Gebara M.J., KulaifY. 2007. A elaboração do conceito de interdisciplinaridade: primeiras aproximações de um projeto de formação continuada de professores da educação básica In: Simp. Pesq. Ensino e História de Ciências da Terra, 1, e Simp. Nac. Ensino de Geologia no Brasil, 3, Campinas, 4-8.09.2007. Anais... Campinas, DGAE/IG/Unicamp. (CD-ROM).

Giordan M. O papel da experimentação no ensino de ciências. Química Nova na Escola, 10:43-49. Novembro, 1999.

Gonçalves P.W., et al. 1994. Trajetória de aperfeiçoamento de uma experiência de integração de ensino e pesquisa de Geologia introdutória para alunos de Biologia. In: Simp. de la Enseñanza de Geología. 1994. Córdoba: AEPECT. Rev. de la Enseñanza de las Ciencias de la Tierra, 3(n. Extra):40-43.

Guimarães O.M. 2010. O Papel Pedagógico da Experimentação no Ensino de Química. In: Guimarães O. M. Novos materiais e novas práticas pedagógicas em química: experimentação e atividades lúdicas. 2010. Curitiba: Departamento de Química da UFPR. 168.

IdicionárioAulete, 2008. URL: http://aulete.uol. com.br/site.php?mdl=aulete_digital. Acesso: 15.07.2013.

Imbernon R.A. et al. 2009. Experimentação e interatividade (hands-on) no ensino de ciências: a prática na praxis pedagógica. Experiências em Ensino de Ciências, 4(1):79-89. Maio 2009.

Jiménez Aleixandre M.P. 1998. Diseño curricular: indagación y razonamiento con el lenguaje de las ciencias. Enseñanza de las Ciencias, 16(2):203-216.

Jiménez Aleixandre M.P. 2003. El aprendizaje de las ciencias: construir y usar herramientas. In: Jiménez Aleixandre M.P (coord.). 2003. Enseñar ciencias. Barcelona: Graó. 13-32p

Kondo M.M., Rosa V.A.M. 2007. Protótipo de reator anaeróbico: tratamento de esgoto doméstico nas escolas. Química Nova na Escola, 26: 33-36. Novembro 2007.

Ledley T.S., et al. 2012. EarthLabs. An Earth System Science laboratory module to facilitate teaching about climate change. The Earth Scientist, 28(3):19-24.

Lorenz K.M. 2008. Ação de instituições estrangeiras e nacionais no desenvolvimento de materiais didáticos de ciências no Brasil: 1960-1980. Rev. Educação em Questão, 31(17):7-23.

Moreira, M.A, Axt, R. (org.). 1991. Tópicos em Ensino de Ciências. Porto Alegre. 1991.

Morin E. 2003. A cabeça bem-feita: repensar a reforma, reformar o pensamento. Trad. Eloá Jacobina. $8^{\text {a }}$ Ed. Rio de Janeiro: Bertrand Brasil. 128p.

Orion N. 2001. A educação em Ciências da Terra. Da teoria à prática-implementação de novas estratégias de ensino em diferentes ambientes de aprendizagem. In: Marques L., Praia J. (Coords). 2001. Geociências nos currículos dos ensinos básico e secundário. Aveiro: Universidade. 93-114p.

Paixao M.F., Cachapuz A. 1999. La enseñanza de las ciencias y la formación de profesores de enseñanza primaria para la reforma curricular: de la teoría a la práctica. Enseñanza de las Ciencias, 17(1):69-78.

Paschoale C., Carneiro C.D.R. 1976. Criação de recursos de ensino dentro de um sistema de multi-meios no Depto. Geologia Geral do IG/USP. In: Reun. anual SBPC, 28, Brasília. Res. Com... Brasília: SBPC. 705p. 1976.

Piranha J.M., Carneiro C.D.R. 2006. Contributos da educação em Geociências para o exercício da interdisciplinaridade. In: Simpósio Ibérico do Ensino da Geologia, 1, Aveiro. 2006. e Simposio sobre Enseñanza de la Geología, 14, Aveiro. 2006. Livro de Actas... Aveiro: AEPECT. 389-393p.

Rampazzo L. 2005. Metodologia científica. $3^{\mathrm{a}}$ ed. São Paulo: Ed. Loyola. 144p.

Ribeiro et al., 2007. Interdisciplinaridade por meio da concepção de ciclo da água em uma bacia de drenagem de Campinas, SP. In: Simp. Pesq. Ensino e História de Ciências da Terra, 1, e Simp. Nac. Ensino de Geologia no Brasil, 3, Campinas, 4-8.09.2007. Anais... Campinas, DGAE/IG/Unicamp. (CD-ROM).

Rodrigues L.Z., Wesendonk F.S., Terrazzan E.A. 2012. Seleção e utilização de atividades experimentais em aulas de biologia e física do ensino médio. In: ANPED SUL Brasil, 9. 2012. Proc... ANPED. URL: http://www.ucs.br/etc/conferencias/index.php/anpedsul/9anpedsul/paper/viewFile/2823/290. Acesso 10.07.2013.

Sardà A., Sanmartí N. 2000. Enseñar a argumentar científi camente: un reto de las clases de ciencias. Enseñanza de las Ciencias, 18:405-422.

Séré M.G. 2002. La enseñanza en el laboratorio. ¿Qué 
podemos aprender en términos de conocimiento práctico y de actitudes hacia la ciencia? Enseñanza de las Ciencias, 20(3):357-368.

Schwab J. The teaching of science. Cambridge (MA): Harvard University Press. 1962.

Tavares R. 2004. Aprendizagem significativa. João Pessoa: Conceitos, 10:55-60.
Toledo M.C.M. 2002. Geologia/Geociências no Ensino. In: Seminário Nacional sobre Cursos de Geologia. Campinas: Unicamp. (Apres. oral). Abril 2012.

Williams Jr. R.S. 2000. A modern Earth narrative: what will be the fate of the biosphere? Technology in Society, 22:303-339. 